\title{
Back to the embryonic stage: Nodal as a biomarker for breast cancer progression
}

\author{
Menashe Bar-Eli* \\ See related research by Strizzi et al., http://breast-cancer-research.com/content/14/3/R75
}

Abstract
The embryonic morphogen Nodal, a member of
the transforming growth factor- $\beta$ superfamily, is not
expressed in the majority of normal adult tissues.
However, a growing body of evidence indicates that
Nodal expression re-emerges in a number of human
cancers, including melanoma, glioma, endometrial,
and prostate cancers. Reactivation of Nodal signaling
in these tumors contributes to their aggressiveness.
Strizzi and colleagues, in a paper published in this
issue of Breast Cancer Research, investigate the clinical
significance of Nodal expression in breast cancer. They
report that Nodal expression is significantly greater
in malignant versus benign breast disease. More
importantly, Nodal levels correlated with grading,
staging, and lymph node involvement, independent of
the estrogen receptor/progesterone receptor or HER2
status. Collectively, these data suggest that Nodal could
serve as a potential biomarker for invasive disease and
a potential therapeutic target in breast cancer.

Significant advances have been made in breast cancer research in relation to early detection and therapy. Contributions from the area of biomarker discovery have enabled us to identify molecular signatures, some of which have been exploited for diagnosis, prognosis and as therapeutic targets. For example, it is well established that the expression of estrogen receptors (ERs) and progesterone receptors (PRs) in breast cancer tissue not only correlates with survival but also predicts the therapeutic efficacy of hormonal therapy. Likewise, the expression of the epidermal growth factor receptor HER2 in breast cancer tissues also prognosticates disease progression, patient survival, and response to biologic

*Correspondence: mbareli@mdanderson.org

MD Anderson Cancer Center, Department of Cancer Biology, Houston, TX 77030, USA therapy employing antibodies that target breast cancer cells overexpressing the HER2 receptor. However, given the heterogeneity of breast cancer among patients and of breast cancer cells within the same cancer tissue(s), not all patients express clinically useful levels of these receptors. For the category of 'triple negative' breast cancer patients who do not express hormone receptors nor HER2, therapy typically consists of a combination of surgery, radiation and chemotherapy. Therefore, dedicated efforts are still needed to identify prognostic biomarkers expressed in a broader fraction of breast cancer patients that would transcend the categories of ER/PR+, HER2+ and triple negative, and be informative of disease outcome.

In the paper by Strizzi and colleagues published in this issue of Breast Cancer Research [1], the authors investigate the clinical significance of Nodal expression in breast cancer. Previously, several of these investigators introduced the discovery of the re-emergence of the embryonic morphogen Nodal (a member of the TGF-beta superfamily) in certain types of aggressive human cancers, including melanoma, glioma, endometrial, and prostate [2]. In the current translational study, the authors determined by immunohistochemistry the level of Nodal expression in a series of breast tissues from a cohort of 431 patients previously diagnosed with benign or malignant breast disease. The patients with malignant breast disease were further grouped based on ER/PR and HER2 status, grading, staging and lymph node involvement. The data reveal that Nodal expression, generally not detected in normal tissues, is significantly greater in malignant versus benign breast disease. Most interestingly, Nodal levels correlated with the degree of advanced disease as represented by grading, staging and lymph node involvement, regardless of the ER/PR or HER2 status in the samples analyzed. Although further prospective studies in a larger cohort would be needed to determine the effects of Nodal on patient survival, these data strongly suggest a role for Nodal during the progression of breast cancer. These observations are in agreement with previous studies by members of this group showing increased Nodal expression in advanced 
stage or metastatic melanoma and prostate carcinoma [3-5]. In melanoma, Nodal is regulated by Notch 4 and is associated with vasculogenic mimicry [6,7]. To further investigate the potential of Nodal as a predictive biomarker, the authors also describe in their study the anti-proliferative and pro-apoptotic effects in two human breast cancer cell lines treated with a Nodal function blocking antibody. These observations require preclinical validation in follow-up studies, but nevertheless suggest that Nodal could represent an attractive therapeutic target in breast cancer.

This study highlights how recent advances in specific areas of breast cancer research have enabled us to characterize the re-emergence of specific embryonic signaling pathways, such as Nodal, thus contributing to our understanding of the molecular mechanisms that regulate cancer cell plasticity and aggressiveness [3]. Exploiting the molecular underpinnings of these embryonic pathways in cancer can result in the discovery of novel biomarkers expressed in a broader population of cancer patients, thus complementing traditional biomarkers already in use, and thereby increasing the number of patients for which clinically useful information can be obtained to predict survival and therapeutic outcome.

Abbreviations

$E R$, estrogen receptor; PR, progesterone receptor.

\section{Competing interests}

The author declares that they have no competing interests.
Published: 24 May 2012

\section{References}

1. Strizzi L, Hardy KM, Margaryan NV, Hillman DW, Seftor EA, Chen B, Geiger XJ, Thompson EA, Lingle WL, Andorfer CA, Perez EA, Hendrix MJC: Potential for the embryonic morphogen Nodal as a prognostic and predictive biomarker in breast cancer. Breast Cancer Res 2012, 14:R75.

2. Hendrix MJC, Seftor EA, Seftor REB, Kasemeier-Kulesa J, Kulesa PM, Postovit L-M: Reprogramming metastatic tumour cells with embryonic microenvironments. Nat Rev Cancer 2007, 7:246-255.

3. Postovit L-M, Margaryan NV, Seftor EA, Kirschmann DA, Lipavsky A, Wheaton WW, Abbott DE, Seftor REB, Hendrix MJC: Human embryonic stem cell microenvironment suppresses the tumorigenic phenotype of aggressive cancer cells. Proc Natl Acad Sci U S A 2008, 105:4329-4334.

4. Lawrence MG, Margaryan NV, Loessner D, Collins A, Kerr KM, Turner M, Seftor EA, Stephens CR, Lai J; APC BioResource, Postovit LM, Clements JA, Hendrix MJ: Reactivation of embryonic nodal signaling is associated with tumor progression and promotes the growth of prostate cancer cells. Prostate 2011, 71:1198-1209.

5. Strizzi L, Hardy KM, Kirsammer GT, Gerami P, Hendrix MJ: Embryonic signaling in melanoma: potential for diagnosis and therapy. Lab Invest 2011, 91:819-824.

6. Hardy KM, Kirschmann DA, Seftor EA, Margaryan NV, Postovit LM, Strizzi L, Hendrix MJ. Regulation of the embryonic morphogen Nodal by Notch4 facilitates manifestation of the aggressive melanoma phenotype. Cancer Res 2010, 70:10340-10350.

7. McAllister JC, Zhan Q, Weishaupt C, Hsu MY, Murphy GF: The embryonic morphogen, Nodal, is associated with channel-like structures in human malignant melanoma xenografts. J Cutan Pathol 2010, 37 Suppl 1:19-25.

doi: $10.1186 /$ bcr3177

Cite this article as: Bar-Eli M: Back to the embryonic stage: Nodal as a biomarker for breast cancer progression. Breast Cancer Research 2012, 14:105. 